\title{
SOLVING A NAVIGATION PROBLEM WITH THE TOTAL ELECTRON CONTENT MODEL GEMTEC
}

\author{
A.A. Kholmogorov \\ Irkutsk State University, \\ Irkutsk, Russia,varagon007@yandex.ru \\ V.B. Ivanov \\ Irkutsk State University, \\ Irkutsk,Russia,ivb@ivb.baikal.ru
}

\author{
O.A. Gorbachev \\ Irkutsk Branch of Moscow State Technical University of Civil \\ Aviation, Irkutsk, Russia, gorbachev_oa@mail.ru
}

\begin{abstract}
This article explores the possibility of improving the accuracy of positioning in single-frequency satellite radio navigation equipment through the use of the empirical model of the total electronic content GEMTEC. The effectiveness of this model is compared with that of the Klobuchar model, which is recommended for the GPS interface control document. We conducted testing at our observation points, using data from the international network of IGS stations in the GPS system. The use of the international network allowed us to select a long period of time for the testing from 2001 to 2017. As a result, it was shown that the GEMTEC
\end{abstract}

\section{INTRODUCTION}

One of the major sources of positioning errors in global navigation satellite systems (GNSS) is an additional delay in navigation signal propagation in Earth's ionosphere. Absolute values of these errors can range from units to tens of meters. Single-frequency navigation receivers use mathematical models of the ionosphere to correct ionospheric errors. An output parameter of these models is the total electron content (TEC), which determines the time of the additional delay in navigation signal propagation. The GPS Interface Control Document (ICD) [Interface Control Document, 2018] recommends using the Klobuchar ionospheric model [Klobuchar, 1987] to correct the ionospheric delay. The Klobuchar model provides vertical TEC for a given geographical location and time, using eight input coefficients, transmitted at regular intervals in GPS navigation messages. The model was constructed as a very simplified computational scheme for saving computational resources of navigation equipment. It allows us to compensate, on average, 50-60\% of the additional ionospheric delay [Klobuchar, 1986]. Obviously, under current conditions such accuracy of the model is not satisfactory. Note that attempts are being made to modify this model.

For example, the paper [Tong et al., 2017] is devoted to the improvement of the accuracy of the Klobuchar model for high latitudes. There are, however, a number of ionospheric models with higher accuracy of TEC reproduction than the Klobuchar model. These models could become an alternative to the Klobuchar model. The most famous of them is the International Reference Ionosphere (IRI) [Bilitza, 1990]. Also popular is the NeQuick model [Dudeney, 1978], focused on the use of GALILEO in model can significantly reduce the average positioning errors as compared to the Klobuchar model. We also demonstrate the possibility of introducing the GEMTEC model and its full-featured use in single-frequency home-class receivers, for example, in the Russian receiver MNP-M7.

Keywords: GPS, single-frequency receiver, ionosphere models.

GNSS. Nevertheless, both of these models originally reproduce the vertical distribution of electron density $N_{\mathrm{e}}$. The TEC value required to solve the navigation problem is calculated in these models by integrating the vertical $N_{\mathrm{e}}$ distribution. This method of determining TEC seems redundant in terms of computational burden. Currently, there are a large number of experimental measurements of TEC under various conditions in different geographical areas. It therefore seems appropriate to create empirical models able to directly reproduce the total electron content. Two such models were developed almost simultaneously and independently a few years ago. We are talking about the NTCM_GL model [Jakowski et al., 2011] and our GEMTEC model [Ivanov et al., 2011].

These models use almost the same array of primary experimental data, but fundamentally differ in methods of processing these data. The NTCM_GL model approximates primary data by a certain set of mathematical functions with the optimal selection of corresponding coefficients. The GEMTEC model uses the expansion of raw data in natural orthogonal functions (method of principal components) [Jolliffe, 2002 ]. The comparative analysis of these two models carried out in [Ivanov et al., 2016] has demonstrated the advantage of the GEMTEC model. It would, however, be interesting to assess the effectiveness of the GEMTEC model directly in solving the navigation problem.

\section{TESTING OF THE GEMTEC MODEL}

The GEMTEC model is described in detail by Ivanov et al. [2011]. It is based on the method of principal components, which can significantly compact the original data array and filter out the noise fluctuations contained therein. The model is a compact block of 
numerical data, which comprises natural orthogonal functions and coefficients of the expansion of initial data in these functions. The initial data used for constructing this model are Global Ionosphere Maps (GIM), produced by the Center for Orbit Determination in Europe (CODE) for the period from 2003 to 2012. To calculate TEC in the GEMTEC model, the corresponding program addresses to the data block by interpolating to input parameters: geographic latitude and longitude, time of day, month and day of the month, level of solar activity, determined from $F 10.7$ - the index of solar radiation intensity at a wavelength of $10.7 \mathrm{~cm}$. When using the GEMTEC model, we carry out only a series of simple arithmetic operations without calculating any functions (unlike the NTCM_GL model). This ensures high calculating speed.

At the first stage of assessing the effectiveness of the GEMTEC model, we evaluated the quality of reproduction of primary TEC data by the model. Figure depicts typical time variations of vertical TEC $I(t)$ at a fixed mid-latitude point $45^{\circ} \mathrm{N}, 0^{\circ} \mathrm{E}$. It shows a $120 \mathrm{hr}$ interval $t$ (horizontal axis). The vertical axis represents $I(t)$ in TECU.

The solid line indicates time variations of TEC from GIM; the dashed-dot lines, the calculation by the GEMTEC model; the dashed line, the calculation by the Klobuchar model. It can be seen that the GEMTEC model provides a much better reproduction of experimental TEC values than the Klobuchar model.

Then, we analyzed its efficiency in solving the navigation problem. For this purpose, we tested the Klobuchar and GEMTEC models, using the RINEXPVT program from the GPS Toolkit package [Tolman, Harris, 2004]. To solve the navigation problem, real pseudoranges, obtained from IGS stations, as well as data from broadcast ephemerides from respective RINEX files were applied to the RINEXPVT program input. The navigation problem was solved using C/A-code measurements. We arbitrarily selected five stations located at moderately low, middle, and moderately high latitudes. We used data acquired on the $22 \mathrm{~d}$ of each month from 2001 through 2011. Errors in coordinates of the phase center of northsouth, west-east antennas and height were averaged for each day. From these errors for each day, we determined the total (3D) positioning error. Then, we found the total errors averaged over all days. Table 1 lists the corresponding values for the tested stations. The last table line shows data averaged over all the sta-

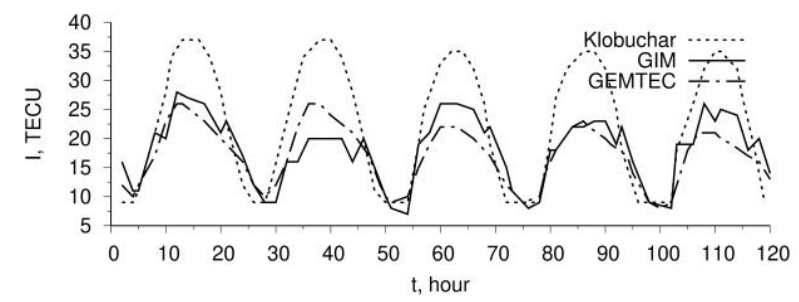

Time variation of vertical TEC for 5 days according to GIM maps (solid line), Klobuchar model (dashed line), and GEMTEC model (dash-and-dot line) tions. All values are in meters. The results presented in Table 1 demonstrate that the GEMTEC model is much more effective than the Klobuchar model.

We carried out a similar testing at our observation point in Irkutsk with Russian navigation receivers MNP-M7, produced by the Izhevsk radio manufacturing plant. In one of the receivers, we used the standard Klobuchar model; in another, the GEMTEC model. We made 50 24-hour measurement sessions in the spring and summer of 2014. The solar activity index during this period varied from moderately low $(F 10.7=$ $95)$ to moderately high $(F 10.7=170)$. We calculated daily average deviations of the measured coordinates of the phase centers of antennas from their true height, north-south (positive value indicates a northward shift) and west-east directions (positive value represents the eastward shift), absolute horizontal and absolute total (3D ) errors, as well as their confidence interval with a probability of 0.95 . Then, we averaged these values over all the 50 sessions. All these errors in meters are listed in Table 2. These results show a significant decrease in the average positioning error in height and latitude in the GEMTEC model compared to the Klobuchar model.

The above results represent the complete solar cycle 2001-2011, generally the same period the data of which were used to build the model. By now the middle of the new solar cycle has passed, therefore we can analyze the effectiveness of the GEMTEC model, taking into account the last five years outside the range of the data used to construct the model. We again used data from the above IGS stations, except for the CHAT station, which did not have a complete set of data. For the remaining four stations, we processed data for the 22 d of each month from 2012 through 2016. We obtained total (3D) positioning errors to solve the navigation problem, using the Klobuchar and GEMTEC models.

The results are combined with those for the previous solar cycle. Thus, Table 3 presents errors averaged over 16 years for each station and errors averaged over all stations.

The comparison between the data from Table 1 and 3 shows that in view of the past five years the effectiveness of the GEMTEC model slightly decreased, but still remains higher than that of the Klobuchar model.

Then, we tested the GEMTEC model at our observation point for fifty daily sessions during the springsummer period of 2017. As in the test made in 2014, we calculated daily average deviations of coordinates of the phase centers of antennas from their true heights, north-south and west-east directions, absolute horizontal and absolute total (3D) errors. Then, we averaged these values over all the 50 sessions. All the errors in meters are listed in Table 4.

The comparison between Tables 2 and 4 shows that the GEMTEC model still has the advantage in positioning accuracy over the Klobuchar model tens of percent for each of the parameters. 
Average total (3D) positioning errors for the IGS network for 2001-2011

Table 1

\begin{tabular}{|l|l|c|c|c|}
\hline Station & Coordinates & $\begin{array}{c}\text { Without } \\
\text { correction, } \mathrm{m}\end{array}$ & Klobuchar model, m & $\begin{array}{c}\text { GEMTEC } \\
\text { model, } \mathrm{m}\end{array}$ \\
\hline $\mathrm{CHAT}$ & $43.6^{\circ} \mathrm{S}, 176.2^{\circ} \mathrm{E}$ & 3.67 & 0.87 & 0.49 \\
\hline $\mathrm{NRC} 1$ & $45.4^{\circ} \mathrm{N}, 75.6^{\circ} \mathrm{W}$ & 3.18 & 1.01 & 0.40 \\
\hline TIDB & $35.4^{\circ} \mathrm{S}, 148.98^{\circ} \mathrm{E}$ & 3.22 & 1.42 & 0.87 \\
\hline $\mathrm{USNO}$ & $39.8^{\circ} \mathrm{N}, 77.0^{\circ} \mathrm{W}$ & 3.51 & 1.16 & 0.62 \\
\hline INVK & $68.3^{\circ} \mathrm{N}, 133.5^{\circ} \mathrm{W}$ & 3.18 & 1.32 & 0.24 \\
\hline \multicolumn{2}{|l|}{ Average over the stations } & 3.35 & 1.16 & 0.52 \\
\hline
\end{tabular}

Table 2

Average positioning errors as derived from measurements in 2014 at our observation point

\begin{tabular}{|l|l|c|c|}
\hline \multirow{4}{*}{ Measured parameter } & \multicolumn{2}{|c|}{ measured parameter values, m } \\
\cline { 2 - 4 } & & Klobuchar model & GEMTEC model \\
\hline \multirow{5}{*}{ Average error } & height & 1.19 & 0.23 \\
\cline { 2 - 4 } & north-south direction & 0.65 & -0.04 \\
\cline { 2 - 4 } & west-east direction & 0.90 & 0.92 \\
\cline { 2 - 4 } & horizontal & 1.15 & 0.95 \\
\cline { 2 - 4 } & total & 1.72 & 1.20 \\
\hline \multirow{5}{*}{ Confidence interval } & height & 6.8 & 5.7 \\
\cline { 2 - 4 } & north-south direction & 3.3 & 3.0 \\
\cline { 2 - 4 } & west-east direction & 3.2 & 2.6 \\
\cline { 2 - 4 } & horizontal & 4.0 & 3.8 \\
\cline { 2 - 4 } & total & 7.6 & 6.2 \\
\hline
\end{tabular}

Table 3

Average total (3D) positioning errors for IGS stations for 2001

\begin{tabular}{|l|c|c|}
\hline \multicolumn{1}{|c|}{ Station } & Klobuchar model, $\mathrm{m}$ & GEMTEC model, $\mathrm{m}$ \\
\hline NRC1 & 0.84 & 0.45 \\
\hline TIDB & 1.26 & 0.72 \\
\hline USNO & 1.01 & 0.83 \\
\hline INVK & 1.01 & 0.36 \\
\hline Average & 1.03 & 0.59 \\
\hline
\end{tabular}

Average positioning errors for measurements in 2017 at our observation point

Table 4

\begin{tabular}{|c|c|c|c|c|c|}
\hline Model & Height & $\begin{array}{c}\text { North-south } \\
\text { direction }\end{array}$ & $\begin{array}{c}\text { West-east } \\
\text { direction }\end{array}$ & Horizontal & $3 \mathrm{D}$ \\
\hline Klobuchar & -0.71 & 0.48 & 0.42 & 0.68 & 1.15 \\
\hline GEMTEC & 0.56 & 0.14 & 0.38 & 0.48 & 0.85 \\
\hline
\end{tabular}

\section{CONCLUSION}

The testing of the effectiveness of the total electron content models demonstrates that the GEMTEC model has an advantage over the Klobuchar model. The testing was carried out using data acquired with both the highclass equipment (IGS network receivers) and homeclass equipment (MNP-M7 receivers). A reduction of the positioning error in the GEMTEC model used instead of the Klobuchar model is tens of percent for each of the parameters. We have demonstrated that the GEMTEC model is effective for the real navigation equipment - the MNP-M7 receiver.

The GEMTEC model requires introducing the solar activity index $F 10.7$. In the testing, the index was entered manually, whereas in real conditions this procedure should be automated. This function in active GNSS has not been implemented yet. However, according to the GLONASS Interface Control Document [Interface Control Document, 2016], with the commissioning of the GLONASS-K satellites with code division of signals the solar activity index will be transmitted in the GLONASS navigation message, thus providing the required automation.

Thus, the total electron content model GEMTEC can be recommended for state-of-the-art single-frequency radio navigation equipment as being able to improve markedly the positioning accuracy in GPS and GLONASS systems.

\section{REFERENCES}

Bilitza D. International Reference Ionosphere 1990. Lanham, 1990, 156 p.

Dudeney J.R. An improved model of the variation of electron concentration with height in the ionosphere. J. Atmos. Terr. Phys. 
1978, vol. 40, no. 2, pp. 195-203. DOI: 10.1016/00219169(78)90024-7.

Interface Control Document, ICD GLONASS CDMA General Description. Edition 1.0. Russian Space Systems. Moscow, 2016, 119 p.

Interface Control Document, IS-GPS-200J. 2018, 224 p.

Ivanov V.B., Gefan G.D., Gorbachev O.A. Global empirical modelling of the total electron content of the ionosphere for satellite radio navigation systems. J. Atmos. Solar-Terr. Phys. 2011, vol. 73, pp. 1703-1707. DOI: 10.1016/j.jastp.2011.03.010.

Ivanov V.B., Gorbachev O.A., Kholmogorov A.A. Comparative quality analysis of models of total electron content in the ionosphere. Geomagnetism and Aeronomy. 2016, vol. 56, no. 3, pp. 318-322. DOI: 10.1134/S0016793216030075.

Jakowski N., Hoque M.M., Mayer C. A new global TEC model for estimating transionospheric radio wave propagation errors. J. Geodesy. 2011, vol. 85, no. 12, pp. 965-974. DOI: 10.1007/s00190-011-0455-1.

Jolliffe I.T. Principal Component Analysis. New York, Springer-Verlag, 2002, 488 p. DOI: 10.1007/b98835.
Klobuchar J.A. Design and characteristics of the GPS ionospheric time-delay algorithm for single-frequency users. Proc. PLANS'86. Las Vegas, 1986, pp. 286-286.

Klobuchar J.A. Ionospheric time-delay algorithm for single-frequency GPS users. IEEE Transactions on Aerospace and Electronic Systems. 1987, vol. 23, no. 3, pp. 325-331. DOI: 10.1109/TAES.1987.310829.

Tolman B., Harris R.B. The GPS Toolkit. Linux J. p. 72.

Tong Bi, Jiachun An, Jian Yang, Shulun Liu. A modified Klobuchar model for single-frequency GNSS users over the Polar region. Adv. Space Res. 2017, vol. 59, no. 3, pp. 833842. DOI: 10.1016/j.asr.2016.10.029.

How to cite this article

Kholmogorov A.A., Ivanov V.B., Gorbachev O.A. Solving a navigation problem with the total electron content model GEMTEC. Solar-Terrestrial Physics. 2019. Vol. 5. Iss. 1. P. 82-85. DOI: 10.12737/stp-51201912. 